\title{
Thermocapillary Convection Experiment Facility of an open Cylindrical Annuli for SJ-10 Satellite
}

\author{
Qi Kang ${ }^{1} \cdot$ Li Duan $^{1} \cdot$ Li Zhang $^{1} \cdot$ Yongli Yin ${ }^{2} \cdot$ Jingsong Yang $^{2} \cdot$ Wenrui Hu$^{1}$
}

Received: 7 July 2015 / Accepted: 12 January 2016 / Published online: 5 May 2016

(C) Springer Science+Business Media Dordrecht 2016

\begin{abstract}
Thermocapillary convection has always been a hot topic of great importance in either crystal growth or thin films science. A space experiment about thermocapillary convection in an open cylindrical annuli pool will be done on SJ-10 satellite. A payload for space experiment has been established, which includes a cylindrical annuli thermocapillary convection system, a thermocouple temperature controlling system and measurement system, a thermal infrared imager, a high-precision displacement sensor, and an experiment controlling system. Some experiments have been done on the ground in order to compare with the results of space experiment. Some results from the ground experiment are shown, such as temperature oscillation, surface oscillation, and flow pattern transfer.
\end{abstract}

Keywords Thermocapillary convection - Cylindrical annulus · Payload · Space experiment $\cdot$ Microgravity fluid physics

\section{Introduction}

Crystal growth has become an important application prospect of space microgravity environments, in order to meet the demands of new modern and high technology

Li Duan

duanli@imech.ac.cn

1 National Microgravity Laboratory / CAS, Institute of Mechanics, Chinese Academy of Sciences, Beijing 100190, China

2 China Astronaut Research and Training Center, Beijing, 100094, China industries based on the development of space technology, such as the microelectronics industries for high-quality semiconductors and alloy materials. Due to the fact that an annular liquid pool has a similar geometric model to the process of Czochralski $(\mathrm{Cz})$ crystal production, its research has received widespread attention. The experimental research of thermocapillary convection in an annular pool was first carried out by Kamotani et al., in which 2cSt silicone oil with 27 Prandtl $(\mathrm{Pr})$ numbers was used to observe the surface of a three-dimensional (3D) oscillatory thermocapillary convection, when the temperature difference exceeded a certain value (Kamotani et al. 1992). In 1992, the first experiment under the microgravity conditions was completed for the purpose of observing stabile thermocapillary convection. Meanwhile, a numerical study was conducted on the steady axisymmetric flow (Kamotani 1999). Later, more experimental studies and numerical simulations regarding oscillatory flow in annular pools were performed by Kamotani et al., in order to discuss the temperature distribution and free surface deformation during oscillatory flow (Kamotani et al. 2000).

During the period from the 1990s to 2004, a series of 3D numerical simulation results regarding the thermocapillary convection of the fluid with equal Pr numbers in an annular pool were reported, along with the results of the thermocapillary convection of the fluid with low Pr numbers in annular shallow and Cz-structure shallow pools. These results confirmed the flow transition, as well as the existence of various oscillation flow patterns. In recent years, more in-depth research has been carried out regarding the thermocapillary convection in annular pools. In 2006, under the conditions of normal gravity and microgravity, the critical value and critical condition of the hydrothermal wave in an annular pool were calculated by Shi and Imaishi et al., for the purpose of analyzing the characteristics of 
the thermocapillary convection and hydrothermal wave of molten silicon in the cases of outer wall heating, while internal wall cooling existed (Shi and Imaishi 2006). In 2007, the 3D buoyant-thermocapillary convection of silicone oil in an annular pool were studied by Peng and Li et al., and the results showed that in the cases of a large Ma number, there were three types of flow states with increasingly complex flow structures (Peng et al. 2007). However, the research regarding the thermocapillary convection of molten silicon in rotating annular pools was completed by Shi and Ermakov et al. Also, in rotating annular pools, the propagation direction of the hydrothermal wave was found to be opposite that of the rotation direction of the pool (Shi et al. 2009). Y. R. Li also gave the good results on thermocapillary convection of a binary mixture in a shallow annular pool (Yu et al. 2015a, b).

The instability of thermocapillary convection short wave and long wave was discussed in the experimental research carried out by Schwabe et al. (1992). Subsequently, the microgravity experiment on thermocapillary convection was completed by D. Schwabe et al., so as to examine the procedure of the route to chaos and report the crystal melt interface temperature oscillation, flow structure, oscillation frequency, critical Ma and other important features (Schwabe and Frank 1999; Schwabe et al. 2003; Schwabe 2006). Kang et al. at NMLC have been dedicated to the experimental study of buoyant - thermocapillary convection for a long term, so as to discuss the critical conditions, oscillation instability and transition process of buoyant thermocapillary convection (Zhu et al. 2011, 2013). D. Schwabe finished experiments under microgravity during the short time of the ballistic flight of a sounding rocket payload to investigate thermocapillary-driven flow of the liquid bridge established by melting the equivalent cylindrical rod of solid sodium nitrate. The temperature oscillation has been measured by five thermocouples, and the critical Marangoni number has been obtained, and the Marangoni instability (Schwabe 2014). Hendrik C. Kuhlmann studied return flow and large-scale flow in thin films (Hendrik 2014).

Massive ground-based experiments have shown that the influence of buoyancy cannot be ignored. The experimental model is a buoyant-thermocapillary coupling convection, and the small-scale (small Bo number) can possibly reduce the influence of the buoyancy. However, it is unable to completely simulate the microgravity experiment. There is found to be scale effects, boundary layer effects, interface morphology differences, and restrictions of the parameter selection scope. In regards to the volume effect problems, the scientific experiments can be carried out in a space microgravity environment. The research results obtained through theoretical analysis and numerical calculation, under the microgravity conditions, need to be validated in the space experiments. The large quantities of experimental results have been compared with previous research results, in order to inspire the demand for space microgravity experiments regarding the above problem.

The space microgravity environment provides a good research platform for study of thermocapillary convection volume effects, in order to realize the working condition of the volume ratio, which is unachievable on the ground. The mutual coupling between the fluid interface and convection shows a complex physical mechanism, and the convection pattern transformation and oscillation behavior are the main characteristics of the convection instability and transition. It is helpful to deeply understand the nonlinear characteristics, flow stability, bifurcated transition, and other basic laws of the thermocapillary flow system, and it is also beneficial to realize and improve the processing and chemical technology of the ground and space materials.

The present study is initiated in support of the microgravity experiment "Space experiment on surface wave of thermocapillary convection", which will be performed aboard the SJ-10 satellite of China in early 2016 (Hu et al. 2014). In this study, the loading development of a space experimental research project of SJ-10 thermocapillary convection has been mainly introduced as well as the basic ground matching scientific experimental research. The scientific goal is to build an annular (cylindrical) liquid pool as a space experiment system of thermocapillary convection, and to study the instability laws and transition process of an annular-system thermocapillary flow. The problem related to the volume effects will be studied for the first time, for the purpose of profoundly understanding the instability and oscillation mechanism of thermocapillary convection. The space experiment content and implementation approach are as follows:

1) The fluid injection volume is changed to form different fluid interface configurations, in order to measure the changes in the multiple physical parameters of the fluid, and to study the volume effects of the thermocapillary convection;

2) An infrared thermal imager is used to measure the changes in the surface temperature of the fluid, and to study the convection pattern transformation of the thermocapillary flow system;

3) A high-sensitivity temperature measurement system, and a surface displacement measurement system are adopted to measure the fluid temperature, as well as the interface time evolution process, for the purpose of studying the fluid oscillation behaviors in the instability and transition processes of the thermocapillary flow system;

4) The bifurcation and transition process of the fluid convection will be analyzed and studied, according to the space experimental measurement results. 
Table 1 The relevant physical parameters for experimental fluid medium

\begin{tabular}{lllllll}
\hline KF96- & $\begin{array}{l}v\left(25^{\circ} \mathrm{C}\right) \text { kinematic } \\
\text { viscosity }\left[10^{-6} \mathrm{~m}^{2} / \mathrm{s}\right]\end{array}$ & $\begin{array}{l}\rho\left(25^{\circ} \mathrm{C}\right) \text { density } \\
{\left[\mathrm{kg} / \mathrm{m}^{3}\right]}\end{array}$ & $\begin{array}{l}\alpha\left(25^{\circ} \mathrm{C}\right) \text { thermal } \\
\text { diffusivity }\left[10^{-7} \mathrm{~m}^{2} / \mathrm{s}\right]\end{array}$ & $\begin{array}{l}\sigma\left(25^{\circ} \mathrm{C}\right) \text { surface } \\
\text { tension }\left[10^{-3} \mathrm{~N} / \mathrm{m}\right]\end{array}$ & $\begin{array}{l}\beta\left(25^{\circ} \mathrm{C} \sim 150^{\circ} \mathrm{C}\right) \text { volume } \\
\text { expansion coefficient }\left[10^{-5} / \mathrm{K}\right]\end{array}$ & $\begin{array}{l}\operatorname{Pr}\left(25^{\circ} \mathrm{C}\right) \\
\text { Prandtl number }\end{array}$ \\
\hline 1 & 1 & 818 & 0.619 & 16.9 & 129 & 16.16 \\
1.5 & 1.5 & 852 & 0.595 & 17.7 & 127 & 25.21 \\
2 & 2 & 873 & 0.714 & 18.3 & 124 & 28.01 \\
\hline
\end{tabular}

\section{Development of the Space Experimental Equipment}

\section{Experimental Model System}

The experimental annular liquid pool has the outer diameter of $R o=20 \mathrm{~mm}$; the inner diameter of $R i=4 \mathrm{~mm}$; and the depth of $d=12 \mathrm{~mm}$. The heating cylinder, which is made of copper material with good thermal conductivity performance, is the center with resistance heating membrane, and can be used to the heat fluid medium in the channel with a cylinder temperature of $T_{h}$. The annular wall is also made of copper material, and the outside edge is attached with a semiconductor refrigeration piece in order to use a Peltier effect for the heat transport. The heat conducted to side wall is transferred to the external support pedestal, for the purpose of reaching the goal of controlling the cooling power by controlling the input current with the annular side wall temperature of $T_{l}$. The temperatures of the inner and outer side walls are monitored and controlled by a thermocouple temperature controller. The bottom of the liquid pool is made of insulation materials with high surface flatness. The top of the liquid pool is equipped with a visible and infrared window $\left(\mathrm{BaF}_{2}\right)$ for the detection records of the laser displacement sensor, as well as the CCD and infrared thermal images. In the experiment, KF96 silicone oil is selected as the fluid medium, and the labels include $1 \mathrm{cSt}, 1.5 \mathrm{cSt}$, and $2 \mathrm{cSt}$. The relevant physical parameters are shown in Table 1 .

In this space environment, due to the loss of gravity, the maintenance of the liquid surface is a key technical problem. The liquid pool system has a variety of anti-climbing measure. At the top of the liquid pool, the non-infiltration materials of experimental working liquid (silicone) are connected to copper plate with anti-climbing wedges. The inner structural design of the liquid pool model is shown in Fig. 1 , and the real photos are shown in Fig. 2.

The dual temperature control system is mainly composed of electro-thermal heating films, a Peltier refrigeration piece, and a thermocouple temperature sensor. The temperature at the low-temperature end of the annular pool wall is controlled at room temperature, and the heat is transferred towards the loading cabinet through six copper support structures. The temperature at the high-temperature end of the control center cylinder is kept at the required temperature difference. All of the components of the temperature control system completed the temperature detection under the unified dispatch and management of the computer system, and passed the PID control temperature with a temperature stability higher than $0.5^{\circ} \mathrm{C}$.

The fluid storage and injection system consists of a DC motor and an actuator, transmission node, hydraulic cylinder, solenoid valve, and piping components. A product from the PI Co., Germany, is selected as the stepper motor, which is made up of a controller and motor (model M-227) with a travel range of $25 \mathrm{~mm}$, and a unidirectional repeatability of $0.1 \mu \mathrm{m}$. The transmission node is mainly used to establish links between the actuator and hydraulic cylinder piston rod, which propelled the hydraulic cylinder piston in advance of the stepper motor, in order to inject the experimental working materials of a hydraulic cylinder into the liquid pool. Contrariwise, the fluid in the liquid pool flows back to the cylinder. The hydraulic cylinder (model ADVU-40-25-P-A, with a travel range of $25 \mathrm{~mm}$ ), solenoid valve (model MSFG12-0D), and piping components are obtained from FESTO Co., Germany. Prior to the satellite orbits, there is no liquid in the liquid pool, and the experimental liquid is stored within the cylinder. The solenoid valve is first opened at the start of the space experiment. According to the program

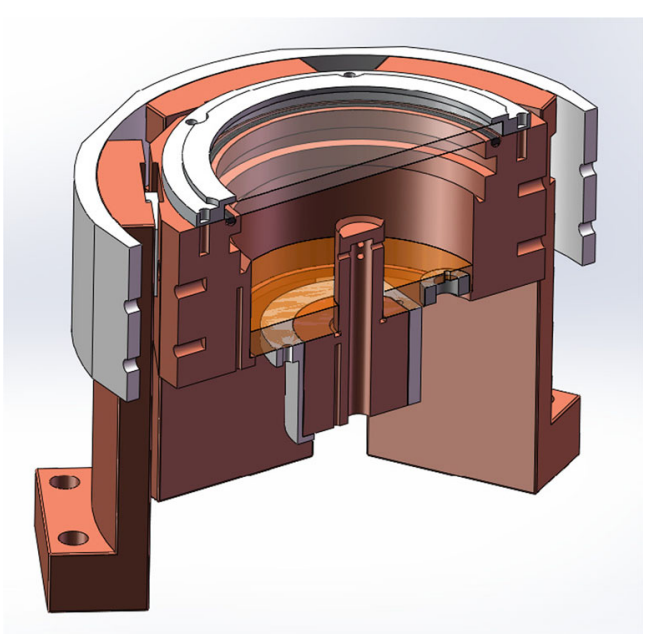

Fig. 1 Model structure of liquid pool 


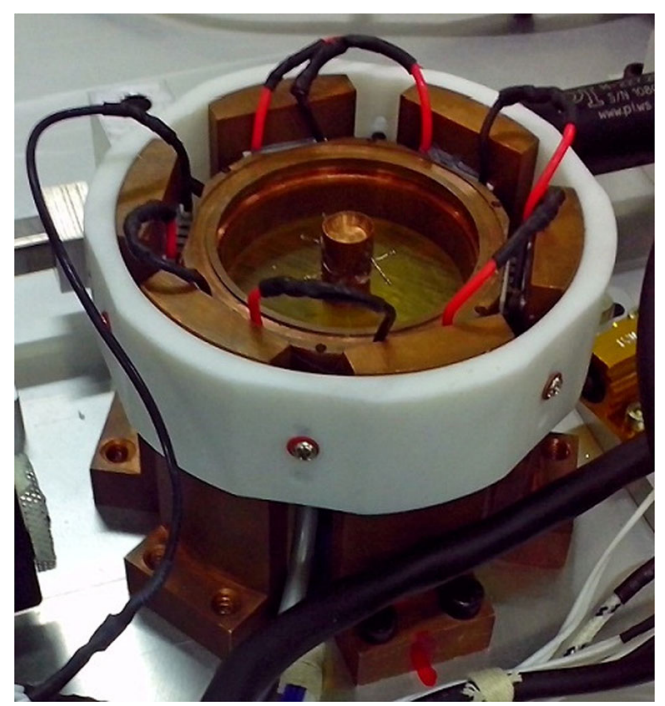

Fig. 2 Real photos of liquid pool

settings, the motors are controlled by a computer system which pushes the cylinder piston in order to inject the right amount of experimental working material (silicone) into the liquid pool. The solenoid valve is shut off at the completion of the liquid injection. The moving step length of the motor is changed to adjust the liquid injection volume, for the purpose of achieving different liquid volume ratios, as shown in Fig. 3.

\section{Experimental Measurement System}

The experimental measurement system consists of a thermocouple, a laser displacement sensor, and an infrared thermal imager. The high-sensitivity temperature and surface deformation measurements are used to study the oscillation and transition of the thermocapillary convection. The distribution changes of the fluid surface temperature are observed to study the flow pattern transformation of the thermocapillary convection.

The thermocouple had the advantages of high measurement precision, wide measurement range, simple structure,

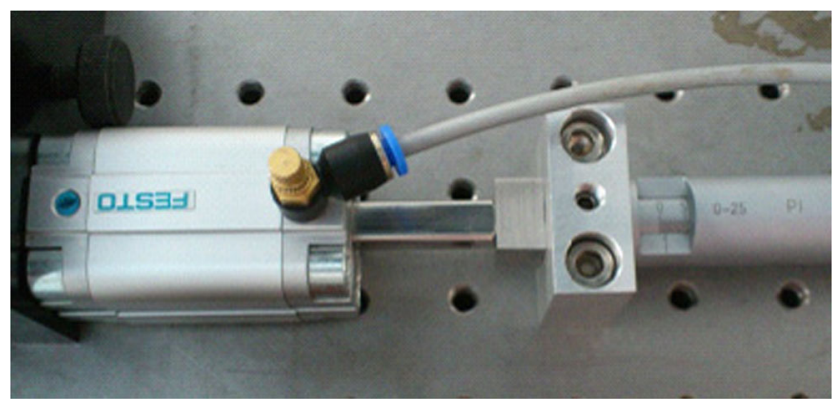

Fig. 3 Liquid storage and injection system and convenient use. In the experimental liquid, the temperature oscillation in the different phase angles is measured by 6 thermocouple temperature sensors. Through computer system management, the temperature signal disposal and magnification are completed by parameter acquisition, processing, and downlink. A ZBDX-HTTK K-type thermocouple (nickel chrome-nickel aluminum) produced by the North University of China is selected as the temperature sensor, of which the thermocouple wire diameter is $0.1 \mathrm{~mm}$, and the single-point temperature data sampling rate is $20 \mathrm{~Hz}$.

In this project, a laser displacement sensor is used with a trigonometry principle for the real-time measurement, in order to record the liquid surface oscillations. The beam of the laser displacement sensor required for the IR window of the liquid pool for the detection of the surface deformations and oscillation caused by the internal liquid convection is as shown in Fig. 4. The laser displacement sensor is a type of non-contact single-point measuring method for photoelectric detection, which has the advantages of a rapid measuring speed, high precision, strong anti-interference ability, small measurement point, and simple operation. A Panasonic HL-C1 ultra-fast laser displacement sensor is used for this payload in order to realize a $100 \mu$ s high-speed sampling, utilizing an ultra-high precision measurement with a resolution of $1 \mu \mathrm{m}$, and a linearity of $\pm 0.1 \%$ F.S. This sensor has a weight of approximately $300 \mathrm{~g}$; a working voltage of DC24V; power of approximately $8.4 \mathrm{~W}$; and a RS232 serial port communication for the data transmission. Using technical reinforcement, this laser displacement sensor has passed the mechanics and thermal environmental experiments required by the satellite engineering.

The TAU 2 infrared camera with a $19 \mathrm{~mm}$ focal length lens, which is produced by the FLIR Co., US, is selected to record the surface temperature of liquid. It is actually a core of thermal imaging camera, so there are small volume and weight, and low power consumption. Some specifications of the IR camera are shown in Table 2

The appearance picture is shown in Fig. 5. The 14-bit original temperature field data are output by this infrared thermal imager. Accordingly, a special digital acquisition

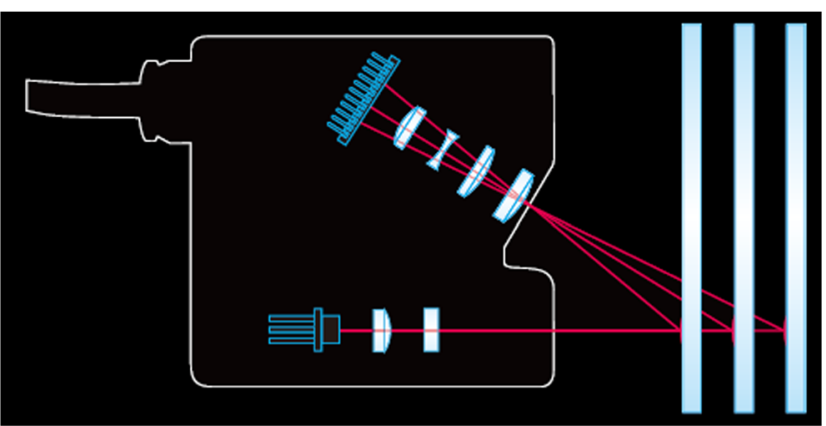

Fig. 4 Measurement principle of displacement sensor 
Table 2 Specifications of TAU 2 infrared camera core

\begin{tabular}{ll}
\hline Parameters & Index \\
\hline The size of image source & $17 \mu \mathrm{m}$ \\
Resolution of the infrared thermal imager & $336 . \times 256$ pixels \\
Weight & $72 \mathrm{~g}$ \\
Power Supply & DC12V \\
Power consumption & $1 \mathrm{~W}$ \\
\hline
\end{tabular}

interface board is set to transfer the compressed infrared thermal image data to a computer system controller via the Ethernet. The technical reinforcement is carried out on the infrared thermal imager in the equipment assembly, for the purpose of adapting it to the mechanics environmental test. The sampling frame rate is controlled at 7 to 8 frames per second. The temperature data are calibrated on the ground, and can be converted to an 8-bit image for the pseudo color display.

\section{Electric Control System}

The control system of the entire space experimental device is divided into two parts. The first is an experimental equipment component controller combined with a motor controller, infrared thermal imager controller, and displacement sensor controller. The second is an experimental payload controller to control the power supply, power shut-off, and space experiment process.

The motor controller, infrared thermal imager controller, and displacement sensor controller, are dominated by commercialized instruments for the development and integrated design, in order to meet the requirements of structure, communication, control, and data interface.

The experimental payload controller is used for the equipment control and management of electrical system in the thermocapillary convection box, receiving the control instructions and data injection. At the same time, on the basis of the experimental process, the transmission experiments regarding the microgravity thermal fluid flow models with different volume ratios are controlled. This equipment is responsible for the power supply management within the thermocapillary convection box, engineering parameters, image data communication, instruction receiving, collection of the engineering parameters, peripheral design, and image acquisition and compression, and its main functions are as follows:

a) The power supply and distribution function: To receive the primary power supply of the +28 VDC which is provided by the capsule payload manager for the power distribution management; to provide the $28 \mathrm{~V}$ power supply for the stepper motor, $24 \mathrm{~V}$ power supply for the displacement sensor, $12 \mathrm{VDC}$ power supply for the solenoid valve, liquid pool heating column, cooling slice, and interface board of the infrared thermal image movement, 6VDC power supply for CCD camera and LED lighting, along with the secondary power distribution for the controller itself.

b) The information communication function: To set the RS485, LVDS, and RS232 buses, as well as the Ethernet bus interface. Through the interface of theRS485 and LVDS buses, the controller is able to realize the information exchange with the capsule payload controller; the acquired engineering parameters, such as

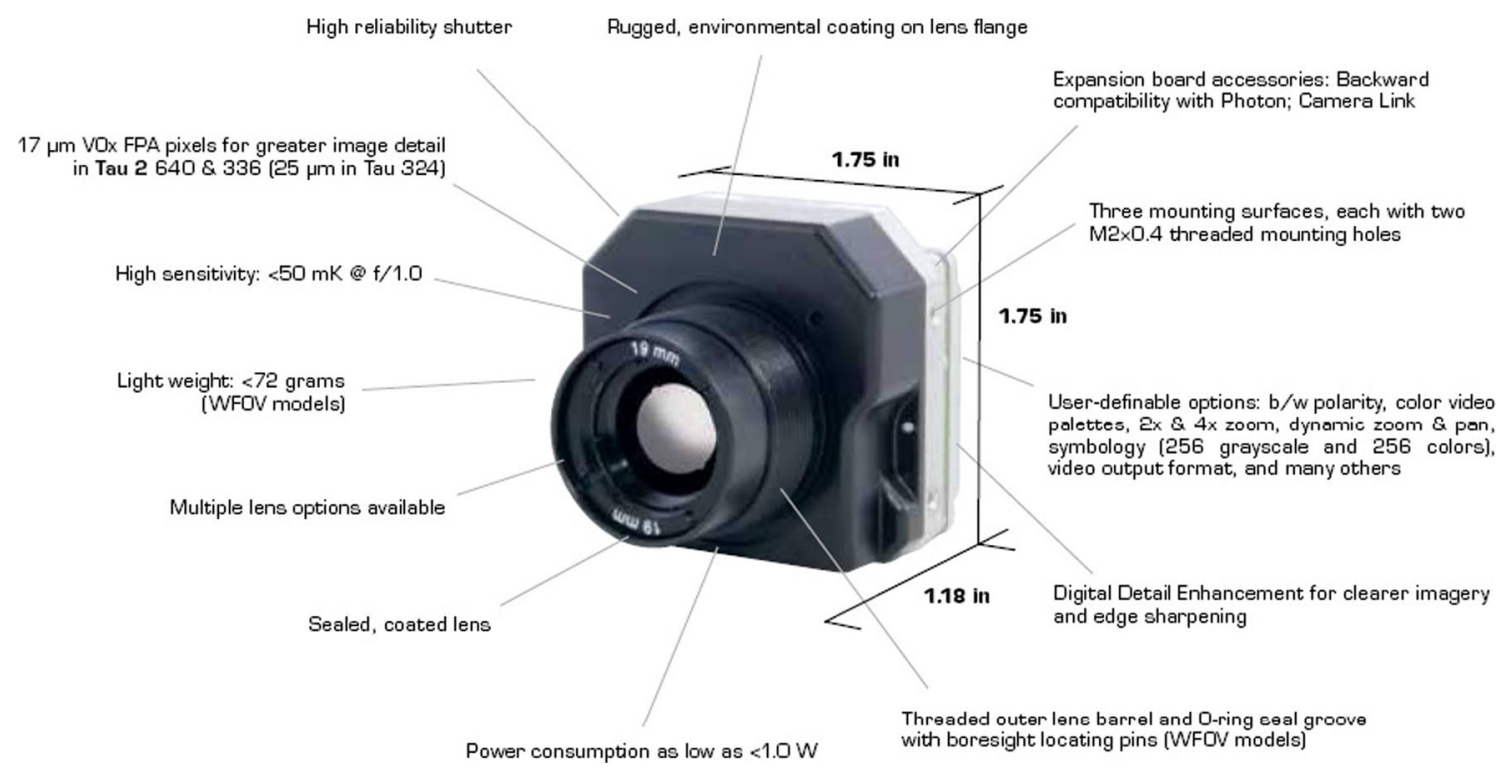

Fig. 5 TAU 2 Infrared camera core 
Fig. 6 Internal structure of the payload

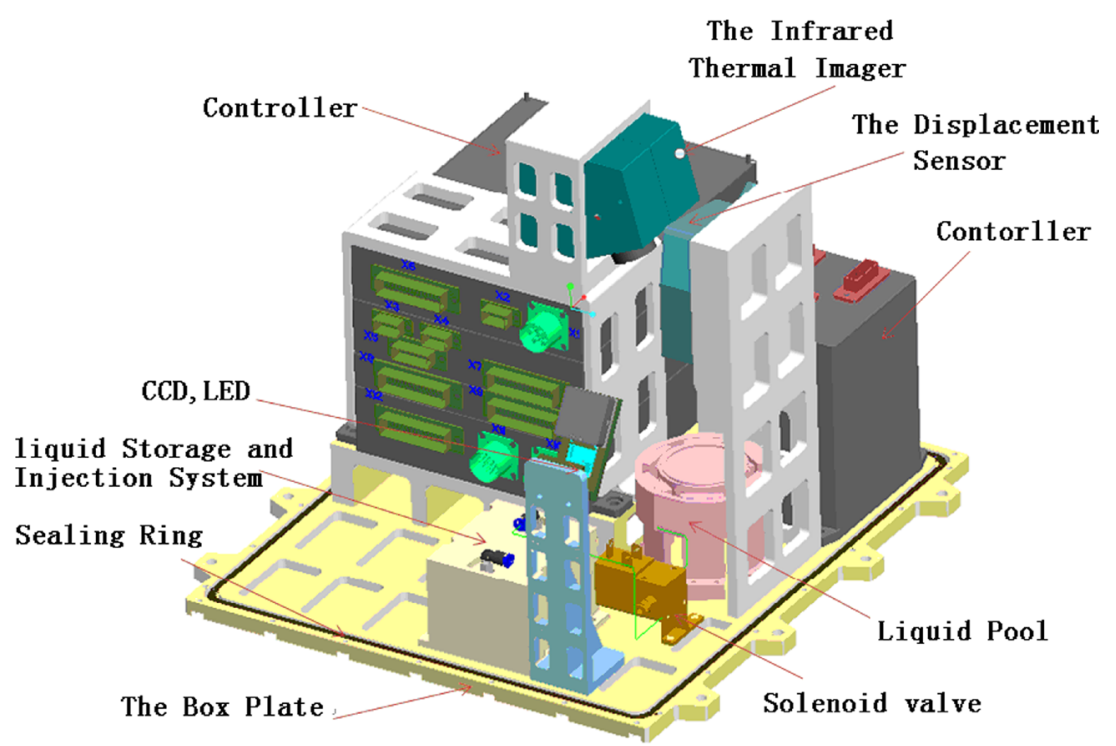

the temperature, along with the state variable information are downloaded through the RS485 and LVDS buses, and the obtained image data are downloaded through the LVDS bus; then, through the RS232 bus interface, the information exchange is realized with the stepper motor and displacement sensor; through the Ethernet bus interface, the infrared thermal image data are acquired.

c) The remote telemetry function: The capsule payload controller is able to control the start-up and shutdown of the thermocapillary convection box controller, through the remote control of the interface. Meanwhile, the telemetry interface of the monitor through the working state of the thermocapillary convection box controller is achieved.

d) The signal processing function: The goal is to receive a thermocouple signal with temperature compensation and transmitting regulation, motor control signals, and displacement sensor signals. These signal collections and processes are carried out by the thermocapillary convection box controller, and based on the indexing table or formula calculation in order to calculate temperature, step length of the stepper motor, liquid level displacement data, and so on.

e) The image processing function: The goal is to acquire the CCD image data for compression processing; receive the temperature field data transmitted by infrared thermal imager; and complete the setting of frame according to the agreement.

f) The control function: Based on the remote control instruction and data injection, the experimental working conditions are selected to adjust the experimental parameters, start the test process, and complete the process control of the heating column, cooling slice, solenoid valve, stepper motor, infrared thermal imager, CCD camera, LED lighting, and displacement sensor.

In accordance with scheduled program, the thermocapillary convection box is used for the video data acquisition, and the switch control to package, store, and download the acquired data. The thermocapillary convection box contained three software configuration items: two CPU software products, and one FPGA software product.

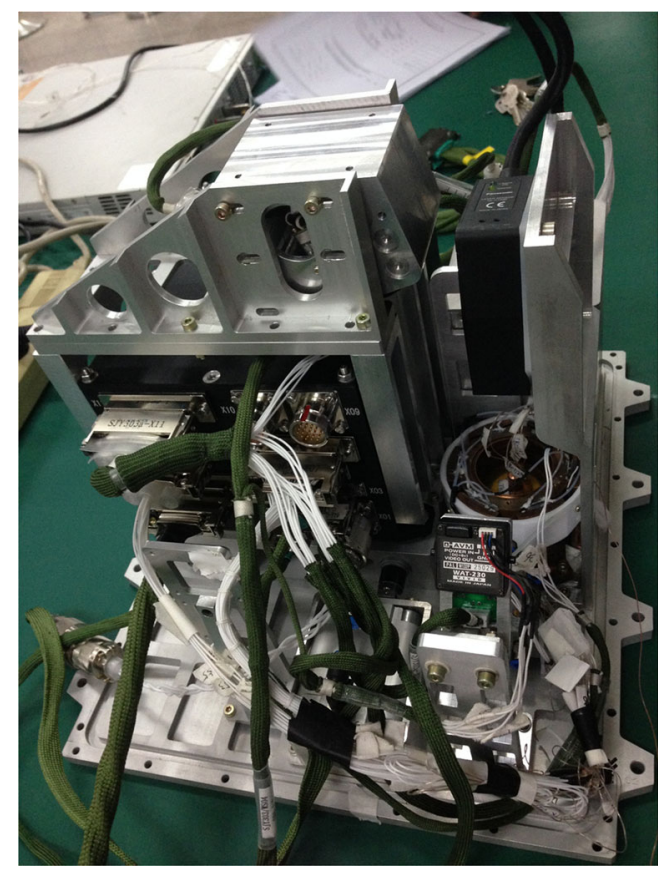

Fig. 7 Photo of internal structure of the payload 


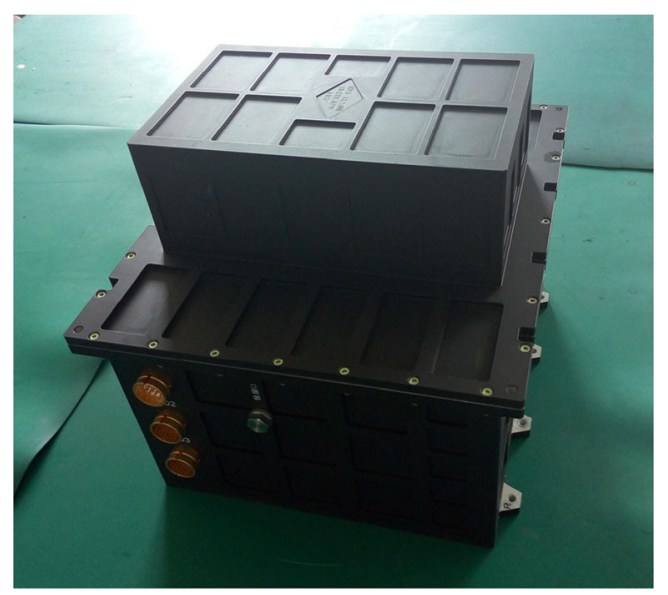

Fig. 8 Payload Box

\section{Payload}

The payload body size is $368 \mathrm{~mm} \times 336 \mathrm{~mm} \times 322 \mathrm{~mm}$; with a weight of $22.9 \pm 0.2 \mathrm{~kg}$; average power consumption of $45 \mathrm{~W}$; and peak power consumption of $90 \mathrm{~W}$. The external data interfaces are the RS485 and LVDS, with a data
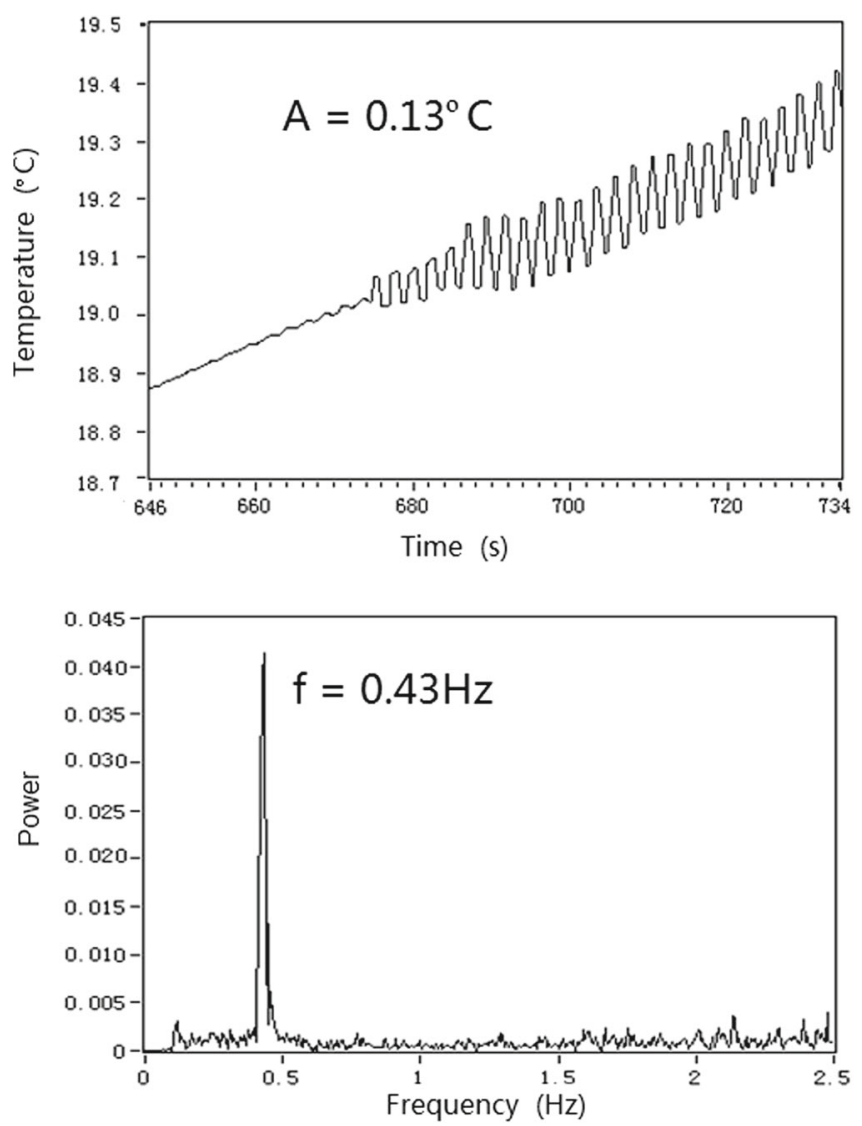

transfer rate of $3 \mathrm{Mbps}$. There are one analog telemetry, four programmed instructions, two remote control instructions, and data injections with an effective length maximum of 24 bytes.

The main structure of the thermocapillary convection box is divided into two layers, composed of three parts, including a main box functional component, an intermediate box component, and a top box. The box is made of a 2A12 material, with a black anodized surface. The minimum thickness of the thin wall is $3 \mathrm{~mm}$, which meet the requirements of the internal and external pressures. The internal box modules are fixed installed. These includes a liquid pool model system module, fluid storage and injection system module, dual temperature control system module, multi-channel temperature acquisition system module, light source system module convection pattern transformation test system module, surface deformation test system module, and a control system module. The internal box is fixed by GB70 M4 sockets. The internal box structure is shown in Fig. 6, internal structure photo of experimental equipment is shown in Fig. 7, and the experimental box is shown in Fig. 8.

A liquid pool model is installed on the box bottom plate. A displacement sensor probe is installed over the liquid
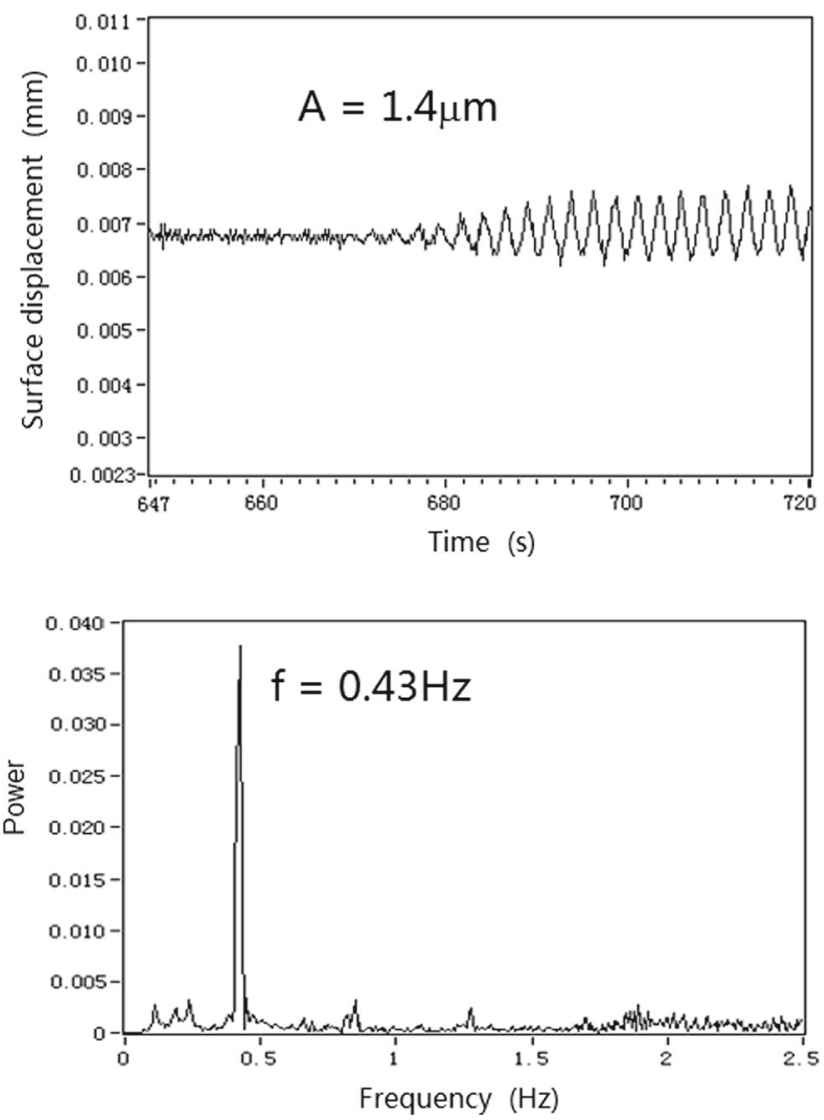

Fig. 9 Original signal (upper) and spectrum analysis (lower) results of the temperature measurement (left), and surface displacement measurement (right) $\operatorname{Pr}=16, R a=76099, M a=49059, B o=1.551, h=3 \mathrm{~mm}$ 
Table 3 The surface temperature patterns and the critical temperature difference at different thickness of liquid layer $\left(0{ }^{\circ} \mathrm{C} \leq \Delta \mathrm{T} \leq 35.0^{\circ} \mathrm{C}\right)$

\begin{tabular}{|c|c|c|c|c|c|c|c|c|c|c|}
\hline $\begin{array}{l}\text { Liquid thickness } \\
\text { h(mm) }\end{array}$ & 0.8 & 1.0 & 1.2 & 1.4 & 1.5 & 1.6 & 1.8 & 2.2 & 2.4 & 3.0 \\
\hline Bond number (Bo) & 0.11 & 0.17 & 0.25 & 0.34 & 0.39 & 0.44 & 0.56 & 0.83 & 0.99 & 1.55 \\
\hline \multirow{5}{*}{$\begin{array}{l}\text { The distribution } \\
\text { of hydrothermal } \\
\text { traveling-wave and } \\
\text { circumferential } \\
\text { standing-wave }\end{array}$} & \multirow{5}{*}{$\begin{array}{l}\text { Hydro- } \\
\text { dynamic } \\
\text { wave }\end{array}$} & \multirow{5}{*}{$\begin{array}{l}\text { Hydro- } \\
\text { dynamic } \\
\text { wave }\end{array}$} & \multirow{5}{*}{$\begin{array}{l}\text { Hydro- } \\
\text { dynamic } \\
\text { wave }\end{array}$} & $\mathrm{m}=0$ & $\mathrm{~m}=0$ & $\mathrm{~m}=0$ & $\mathrm{~m}=0$ & $\mathrm{~m}=0$ & $\mathrm{~m}=0$ & Basic \\
\hline & & & & $m=6$ & $\mathrm{~m}=9$ & $\mathrm{~m}=6$ & $m=6$ & $\mathrm{~m}=1$ & $\mathrm{~m}=1$ & flow \\
\hline & & & & \multirow[t]{3}{*}{$\mathrm{m}=5$} & $\mathrm{~m}=6$ & & $\mathrm{~m}=7$ & $\mathrm{~m}=6$ & \multirow[t]{3}{*}{$\mathrm{m}=6$} & \\
\hline & & & & & $\mathrm{m}=8$ & & $\mathrm{~m}=8$ & $\mathrm{~m}=7$ & & \\
\hline & & & & & $m=7$ & & $m=6$ & & & \\
\hline \multirow{5}{*}{$\begin{array}{l}\text { Corresponding } \\
\text { critical temperature } \\
\text { difference } \Delta T_{c}\left({ }^{\circ} \mathrm{C}\right)\end{array}$} & \multirow[t]{5}{*}{$9.0 \sim$} & \multirow[t]{5}{*}{$10.0 \sim$} & \multirow[t]{5}{*}{$12.0 \sim$} & 9.6 & 11.0 & 10.0 & 10 & 11 & 12.0 & none \\
\hline & & & & 18.0 & 14.0 & $15.5 \sim$ & 15 & 13 & 14.5 & \\
\hline & & & & $26.0 \sim$ & 17.0 & & 19 & 16 & $18.5 \sim$ & \\
\hline & & & & & 18.0 & & 26 & $19 \sim$ & & \\
\hline & & & & & $22.0 \sim$ & & $28 \sim$ & & & \\
\hline
\end{tabular}

pool, acquiring the liquid surface reflection beam in the optical window of the displacement sensor measurement probe, and the liquid level height changes in the measurement range of the displacement sensor. The infrared imager component is over the liquid pool with a $65^{\circ}$ depression angle, and the infrared imager lens has a vertical distance of $133 \mathrm{~mm}$ from the liquid pool surface. Both the vibration isolation and the cooling are considered in the fixed support design of the infrared imager. A CCD camera and a LED light source are installed on the same side, to avoid a liquid surface reflective phenomenon in the CCD images. A hydraulic motor and hydraulic cylinder are directly installed at the box bottom plate, and then solenoid valve components are set behind the cylinder liquid outlet.

\section{Experimental Research on the Ground}

\section{Temperature and Surface Oscillation}

In order to better understand the thermocapillary convection mechanism, and to more effectively know the space experimental model, a series of experimental studies regarding the ground are carried out. A 1cSt silicone oil (model KF96-1) is selected as the fluid medium, with a liquid layer thickness of $3 \mathrm{~mm}$. Using the working conditions of $P r=16, R a=76099, M a=49059$, and $B o=1.551$, the thermocouple temperature and displacement sensor measurements are utilized to measure the fluid. It is determined that the temperature oscillations and surface oscillation
Fig. 10 Buoyantthermocapillary convection pattern transformation

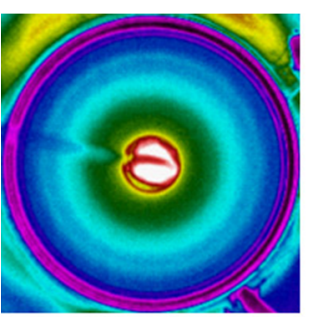

$m=0$

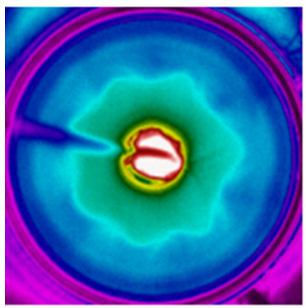

$m=7$

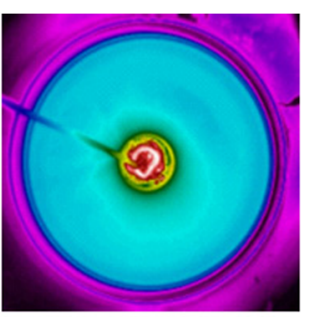

$m=1$

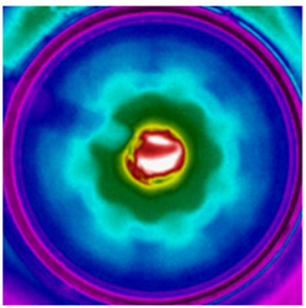

$m=8$

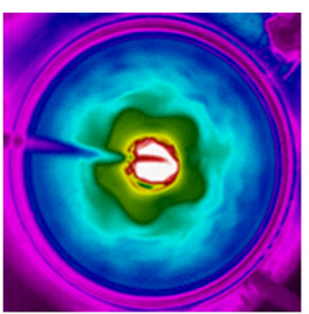

$m=5$

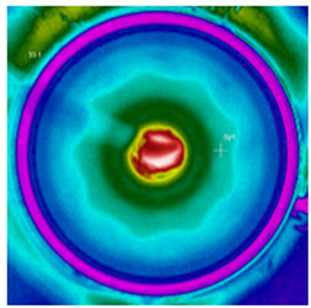

$m=9$

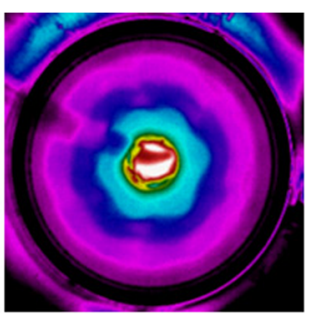

$m=6$

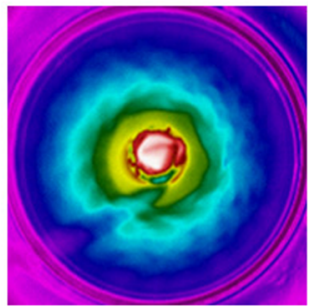

Hydrodynamic wave 
signals appeared almost simultaneously, and with the same frequency characteristics, as shown in Fig. 9.

\section{Convection Pattern Transformation}

In the experiment of this study, an infrared thermal imager is used to shoot the evolutionary process of the surface temperature field during the gradual increase of temperature difference between the internal and external walls, for the same type of 1cSt silicone oil under different thicknesses of liquid layer, for the purpose of quantitatively observing the circumferential temperature the fluctuation laws. It is found that a transition of surface circumferential standingwave mode existed in the convection system of the annular liquid pool. During the increasing of the radial temperature difference in the experiment, a total of 7 standing-wave modes with different wave numbers $(m=0,1,5,6,7,8$, and 9), and a hydrothermal traveling-wave mode (two sets in a spiral-wave delay clockwise and reverse counterclockwise rotation, with a certain angle with the heating wall) are roughly found, as shown in Fig. 10. The radial oscillation exists in seven types of surface standing-wave modal, and the energy was transferred from the wave abdomen to the side wall. Meanwhile, the standing-wave flow field status is a two-dimensional oscillation flow; the traveling wave mode of hydrothermal wave is characterized by circumferential spiral-wave in one-way or two-way rotation; and the wave number changes and temperature turning points are also different in the same warming process, under the different thicknesses of liquid layers. In the range of temperature difference less than $35.0{ }^{\circ} \mathrm{C}$, the surface temperature patterns and the critical temperature difference at different thickness of liquid layer are shown in Table 3. The first critical temperature difference is general between $9-12^{\circ} \mathrm{C}$. Direct transition to the hydrothermal wave only occurs in thin liquid layers $(h<1.2 \mathrm{~mm}$, Bond number $<0.25)$. When the liquid layer is larger than $1.2 \mathrm{~mm}$, it will occurs radial concentric circles oscillation $(m=0)$, and then occurs circumferential standing-waves. The patterns observed in $1.5 \mathrm{~mm}$ liquid layer are the most abundant $(m=0,9,6,8$, 7 ), it may be reasons of the suited aspect ratio.

\section{Space Experimental Scheme}

A total of 15 sets of space microgravity experiments are preset for the thermocapillary convection experiment payload. Through the push and pull of the liquid injection motor, the working condition of a specific volume ratio is realized with a volume ratio which ranged from 0.6 to 1.05 , in order to complete the temperature and surface deformation measurement of the thermocapillary convection under a linear warming mode, and stepped warming mode, respectively. The maximum temperature difference is set as $25^{\circ} \mathrm{C}$ in the first set of experiments. Subsequently, the maximum temperature difference in each set of experiments is determined by a detailed analysis of the previous experimental results, and then adjusted through a data injection pattern. It is determined that the adjacent two sets of experiments will be carried out with an interval of at least 2 hours, and the experimental results are downloaded to a surface data receiving station by transit. The surface image analysis and data processing are carried out to complete the scientific research regarding the thermocapillary convection space experiment.

\section{Conclusions}

This space experimental project of the SJ-10 thermocapillary convection surface-wave is based on massive ground research, for the purpose of developing and designing a space experimental payload of thermocapillary convection, or a thermocapillary convection box. The flightmodel development is completed to confirm that the infrared thermal imager, thermocouple temperature measurement system, and displacement sensor are combined for the realtime observation of the fluid temperature field changes, as well as the temperature and surface oscillations. The conversion pattern transformation of the thermocapillary convection flow system is studied, as well as the fluid oscillation behaviors in the instability and transition process of the thermocapillary flow system. The fluid injection volume can be changed to form different fluid interface configurations, in order to measure the changes in the multiple physical parameters of the fluid, and to study the thermocapillary convection volume effects. According to the results of the space experiment measurement, the analysis and research are carried out on the bifurcation and transition process of the fluid convection. The flight models passed the environmental simulation test, and are expected to complete a space experimental mission in April 2016.

Acknowledgments The work is funded by the Strategic Priority Research Program on Space Science, Chinese Academy of Sciences: SJ-10 Recoverable Scientific Experiment Satellite (Grant No. XDA04020405 and XDA04020202-05), and by the National Natural Science Foundation of China (Grant No.11372328).

\section{References}

Kamotani, Y., Lee, J.H., Ostrach, S., et al.: An experimental study of oscillatory thermocapillary convection in cylindrical containers[J]. Physics of Fluids A: Fluid Dynamics (1989-1993) 4(5), 955-962 (1992)

Kamotani, Y.: Thermocapillary flow under microgravityexperimental results[J]. Adv. Space Res. 24(10), 1357-1366 (1999) 
Kamotani, Y., Ostrach, S., Masud, J.: Microgravity experiments and analysis of oscillatory thermocapillary flows in cylindrical containers[J]. J. Fluid Mech. 410, 211-233 (2000)

Shi, W.Y., Imaishi, N.: Hydrothermal waves in differentially heated shallow annular pools of silicone oil[J]. J. Cryst. Growth 290(1), 280-291 (2006)

Peng, L., Li, Y.R., Shi, W.Y., et al.: Three-dimensional thermocapillary-buoyancy flow of silicone oil in a differentially heated annular pool[J]. Int. J. Heat Mass Transfer 50(5), 872-880 (2007)

Shi, W.Y., Ermakov, M.K., Li, Y.R., et al.: Influence of buoyancy force on thermocapillary convection instability in the differentially heated annular pools of silicon melt[J]. Microgravity Sci. Technol. 21(1), 289-297 (2009)

Yu, J.J., Li, Y.R., Wu, C.M., Chen, J.C.: Three-dimensional thermocapillary-buoyanc y flow of a binary mixture with Soret effect in a shallow annular pool. Int. J. Heat Mass Transfer 90, 1071-1081 (2015a)

Yu, J.J., Ruan, D.F., Li, Y.R., Chen, J.C.: Experimental study on thermocapillary c onvection of binary mixture in a shallow annular pool with radial temperature gradient. Exp. Thermal Fluid Sci. 65, 79-86 (2015b)

Schwabe, D., Möller, U., Schneider, J., et al.: Instabilities of shallow dynamic thermocapillary liquid layers[J]. Physics of Fluids A: Fluid Dynamics (1989-1993) 4(11), 2368-2381 (1992)
Schwabe, D., Frank, S.: Experiments on the transition to chaotic thermocapillary flow in floating zones under microgravity[J]. Adv. Space Res. 24(10), 1391-1396 (1999)

Schwabe, D., Zebib, A., Sim, BC.: Oscillatory thermocapillary convection in open cylindrical annuli. Part 1 . Experiments under microgravity[J]. J. Fluid Mech. 491, 239-258 (2003)

Schwabe, D.: Marangoni instabilities in small circular containers under microgravity[J]. Exp. Fluids 40(6), 942-950 (2006)

Zhu, P., Duan, L., Kang, Q.: Transition to chaos in thermocapillary convection. Int. J. Heat Mass Transfer 57, 457-464 (2013)

Zhu, P., Zhou, B., Duan, L., Kang, Q.: Characteristics of surface oscillation in thermocapillary convection. Exp. Thermal Fluid Sci. 35, 1444-1450 (2011)

Schwabe, D.: Thermocapillary liquid bridges and marangoni convection under microgravity-results and lessons learned. Microgivity Sci. Technol. 26, 1-10 (2014)

Hendrik, C.: Kuhlmann, large-scale liquid motion in free thermocapillary films. Microgivity Sci. Technol. 26, 397-400 (2014)

Hu, W.R., Zhao, J.F., Long, M., Zhang, X.W., Liu, Q.S., Hou, M.Y., Kang, Q., Wang, Y.R., Xu, S.H., Kong, W.J., Zhang, H., Wang, S.F., Sun, Y.Q., Hang, H.Y., Huang, Y.P., Cai, W.M., Zhao, Y., Dai, J.W., Zheng, H.Q., Duan, E.K., Wang, J.F.: Space program SJ-10 of microgravity research. Microgravity Sci. Technol. 26, 159-169 (2014) 